\title{
A ESTÉTICA DO DESCONFORTO EM 21 GRAMAS: ENTE A REDENÇÃO E O INFERNO
}




\section{A ESTÉTICA DO DESCONFORTO EM 21 GRAMAS: ENTRE A REDENÇÃO E O INFERNO}

Resumo:

Pretendemos, neste trabalho, identificar as dualidades presentes em 21 gramas, de Alejandro González Iñárritu. Ou seja, como a desintegração de três personagens, em seus percursos, demonstra uma espécie de descida aos infernos, exemplificada na dualidade com a redenção (calcada no âmbito familiar com forte função realista/naturalista).

Palavras chave: 21 gramas; Estética do desconforto; Redenção; Inferno; Real

\section{ESTÉTICA Y LAS MOLESTIAS EN 21 GRAMAS: ENTRE LA REDENCIÓN Y EL INFIERNO}

Resúmen:

Tenemos la intención de este trabajo identificar las dualidades presentes en 21 Gramas, filmado por Alejandro González Iñárritu. En otras palabras, como la desintegración de los tres personajes, en sus viajes, se muestra una especie de descenso a los infiernos, ejemplificada en la dualidad con la redención (basada en la familia con un tono realista fuerte).

Palabras Clave: 21 gramas; Redención; Estetica; Infierno; Real

THE ESTHETICS OF DISCOMFORT IN 21 GRAMAS: BETWEEN REDEMPTION AND HELL

\section{Abstract:}

The purpose of this paper is to identify the dualities present in the film 21 gramas, by Alejandro González Iñárritu. In other words, how the disintegration of three characters, on their ways, demonstrate a kind of "descent into hell", exemplified in the duality with the redemption (grounded in family with function strong realist / naturalist).

Keywords: 21 gramas; Aesthetics of discomfort; Redemption ; Hell; Real 


\section{INTRODUÇÃO}

O uso da descrição em qualquer narrativa faz confirmar a carga do referencial embutido. Os elementos descritivos de referencialidade de uma narrativa são, grosso modo, "provas" incontestes de determinada pulsão, no sentido de se mostrarem como componentes de uma realidade palpável e/ou tangível. Essa evidenciação, algo superficial, em torno da descrição, pode nos sugerir a ênfase, mais clara, de que a construção da realidade se dá por uma ordem vital.

Nesse sentido, a entidade realista é arquitetada pelo suporte da descrição. Suporte este que ilumina objetos e seres à luz da identificação de alta sensação corpórea perante os desmazelos sociais. Ou seja, a promulgação de cunho social se aproxima de uma absorção também cultural, na medida em que salienta, a partir dos objetos em cena (no caso do audiovisual), níveis outros de interpretação que não apenas o "convencional” percurso narrativo.

A tradição literária realista/naturalista se apropriou do elemento descritivo, justamente, com a necessidade de envolver os ditames éticos que a suporta, isto é, a referendar, pela lógica do real, a sensação - ou impressão - de realidades que se desintegram, ou podem se desintegrar. É importante, ademais, salientar que a saturação ou a desintegração são pistas para entendermos meIhor o funcionamento da gênese do processo naturalista/realista literário - por exemplo, do século XIX - em que a validade social tinha papel importantíssimo.

Podemos argumentar, pois, que existe uma lógica/tradição/linhagem de cunho aportado na descrição como guia. E se falamos de descrição, estamos evidenciando/notando uma demarcação imbuída ainda mais na veracidade mimética e representativa, nos deslocamentos do espaço e do tempo. Partindo desses pressupostos em torno da materialidade calcada na presença do real, pela descrição de tom realista/naturalista, poderíamos afirmar que a produção audiovisual contemporânea - mais e mais - utiliza-se da verossimilhança (aqui entendida em seu componente pragmático de demonstração do real) para "sujar" os incômodos do mundo representado, em que os elementos descritivos são essenciais, fazendo surgir, com isso, uma clarificação solta de desintegração e desconforto.

O cineasta Alejandro González Iñárritu, em 21 gramas (2003) utiliza os efeitos da realidade circundante para evidenciar vários contrastes temáticos, instalados na noção de desintegração, percebida como fratura. Essa sensação de fratura é evidenciada em 21 gramas, necessariamente, pelo deslocamento de três personagens em busca do elo de sentido vital, em sofridos périplos na cidade (o cenário abarcador de conflitos): o ex-presidiário Jack (Benicio Del Toro), o professor universitário Paul (Sean Penn) e a jovem viúva Cristina (Naomi Watts). Todos eles irão se transmutar na sensação de fratura, característica presente no cinema de Iñárritu (na parceria com o roteirista Guillermo Arriaga), isto é, um mundo em constante mutação. Tais mudanças, no mais, são válvulas de rearranjo geopolítico (o sintoma da latinidade), globalizado (pessoas em di- 
fícil exercício comunicativo) híbrido (o novo papel das classes sociais urbanas), urbano (a função de uma cidade determinista).

A fratura ganha ainda mais sentido na condição dos três personagens em conflito - pela brutalidade em potencial na condução que desempenham: um doente terminal constrói a vida (Paul), em descompasso com a ânsia da ortodoxia do novo crente (Jack) ou, ainda, da impavidez da felicidade que rui no lar de Cristina e sua família.

Nosso objetivo, com este trabalho, é, portanto, identificar as dualidades presentes em 21 gramas pelo processo de desintegração dos três personagens em seus percursos, demonstrando, dessa maneira, a descida aos infernos, exemplificada na dualidade com a redenção (calcada no elemento familiar com forte função). Com isso, desenha-se uma estética do desconforto, ratificada por uma legitimação do real, a partir da autenticidade descritiva, porém fragmentada.

\section{O REAL FRAGMENTADO}

A obra de Iñárritu está inserida na produção cultural contemporânea como síntese dos rumos que o cinema dito transnacional toma, em suas materialidades de choque, ou de exemplo de um mundo que pode ser tomado e vislumbrado como "diverso", incomum. Nesse contexto, 21 gramas - sua segunda realização em parceira com o roteirista Guillermo Arriaga - carrega as tintas de um projeto que começara em Amores perros (2000) e desembocaria em Babel (2006). Grosso modo, essa "trilogia" engendra discussões em torno do mundo globalizado, na lógica de um tempo em mosaico. Mosaico aqui entendido como a divisão de mundos inseridos na conexão, digamos, do espetáculo midiático contemporâneo.

Os filmes de Iñárritu pertencem a uma estilística incomum: jogam com os níveis de realismo melodramático clássico, e também operam na distinção acelerada e fragmentada da produção contemporânea. De certa maneira, seus filmes se aproximam de realizadores distintos (embora aproximativos, no que se refere às abordagens fragmentadas do cotidiano atual) como Paul Tomas Anderson (Magnólia, 1999), Robert Altman (Short Cuts, 1993), Paul Haggis (Crash, 2004), Quentin Tarantino (Pulp Fiction, 1994), Bryan Singer (Os Suspeitos, 1995); da chave da estetização metalingüística da violência em cenários de forte tensão globalizada como nos filmes dos irmãos Jean Pierre e Luc Dardenne (essencialmente, no tocante à incomunicação envolta nas relações familiares e na xenofobia européia); da abordagem da desumanidade mais explicita como no cinema de Michael Haneke. Ou, ainda, em obras recentes de Gus Van Sant, dos irmãos Joel e Ethan Coen, em seus jogos de apreensão de um mundo colocado em fragmentação no diálogo com o universo pop; e até no contato com Lars Von Trier, em suas empreitadas episódicas (Dogville, Anticristo, Melancolia). 
O mundo vislumbrado em mosaico, é bom frisar, é um mundo em fragmentação. O sentido dessa fragmentação deve ser entendido por efeitos "insanos" de verossimilhança, delineando, portanto, um paradoxo contemporâneo, ou seja, os elementos de veracidade, no mundo globalizado, embaralham e obscurecem o espectador na lógica permeada da apreensão rápida e veloz. Não estamos, aqui circunstancialmente, no campo restrito da abstração ou da relativização do espaço/tempo das preconizações do Cinema Moderno, como por exemplo $O$ ano passado em Marienbad, de Alain Resnais. Por isso, em contraponto, há no cinema de Iñárritu, e em 21 gramas em particular, uma espécie de simples construção conflitiva que se evidencia pela desintegração como marca. Senão vejamos:

Jack, um ex-presidiário, agora crente fanático educa seus dois filhos (na vigília constante e arredia da esposa Marianne) e na deflagração de conflito existencial com seu pastor. Jack praticará um ato moldado no epicentro de 21 gramas, após o acidente que vitimará duas crianças (Katie e Laura) e um homem (Michael), filhas e marido de Cristina. O coração de Michael será transplantado no professor universitário Paul, em estado de saúde terminal. Paul irá atrás de Cristina, após o transplante, e ambos buscarão a vingança na perseguição a Jack. Esse sistema cíclico evidencia um percurso de ordem desintegrativa e fragmentada, pois faz do epicentro trágico (o acidente de automóvel ou a culpa cristã de Jack) o embate com a burguesia tácita elucidada no mundo de Cristina e Paul.

Nesse momento, retomamos as categorias elencadas neste trabalho em relação aos processos descritivos revestidos de veracidade realística, como efeito notado na obra de Iñárritu, principalmente na música contemplativa de Gustavo Santaolla, na fotografia estilizada de Rodrigo Prieto, no roteiro cru de Arriaga e na interpretação visceral dos atores etc. Barthes (2004), ao se apropriar da literatura de Flaubert como elemento de uma nova característica de impressão do mundo, analisa o efeito realístico na decodificação/desnudamento que o escritor francês faz dos recônditos de uma burguesia decadente, em seus códigos de frivolidade, justificados na exatidão de suas práticas sociais e no "rigor" da "representação do real":

A finalidade estética da descrição flaubertiana é toda mesclada de imperativos "realistas", como se a exatidão do referente, superior ou indiferente a qualquer outra função, ordenasse e justificasse sozinha, aparentemente, descrevê-lo - no caso das descrições reduzidas a uma palavra - denotá-los (BARTHES, 2004, p.186).

A denotação da exatidão referencial é a transparência verídica da sanção de um universo de atitudes transitórias, porém fincado no "real concreto" (BARTHES, 187), desempenhando, no mais, uma função crítica de análise do mundo circundante por se permitir, evidentemente, vinculado a uma realidade 
que, grosso modo, modifica-se e se mostra "bárbara", "doente”, incômoda, etc.

Nesse sentido, e em paralelo, 21 gramas aporta a sensação de um apelo realista no sentido de polarizar o sujo e o limpo (o lar opressor cheio de referências ao cristianismo da família de Jack versus a assepsia clara e feliz da residência de Cristina e sua família); esta contradição é ligada - em intenso uso de close-ups - à residência "hospitalar" de Paul, em sua dificuldade nos tratos com a doença coronária terminal, mais a árdua tarefa de engravidar a mulher (Mary), ou em reuniões com colegas professores universitários ensejados no papo intelectual e esnobe.

Outra constatação importante em 21 gramas é a separação entre o incômodo evidenciado no tropel (reforçando aspectos de certa epopéia aventuresca, própria dos filmes policiais em suas jornadas de perseguição e punição) com os momentos de contemplação em planos fechados, reforçando, com grande intensidade, os desconsolos dos rostos em sofrimento (Jack em suas orações e choros punitivos; Cristina, no consumo de drogas; Paul, na sua dificuldade circunstancial de locomoção ou de averiguação do mundo ao redor).

Tal contradição entre planos gerais e íntimos é instrumento usado para reforçar o apelo descritivo de mundo, modelar os níveis de desintegração dos personagens (em mosaico - ou em quebra cabeças - nas oscilações constantes em pontos pretéritos e futuros) e volumar um chamamento do desconforto de ordem social. Trata-se, pois, de uma antítese sustentada por uma contradição quase paradoxal: seres errantes em busca da redenção descendo ao inferno de tom pessimista que a vida apreende em suas fases. O peso da morte se equiparar a meros 21 gramas só retoma algo já presente em Amores perros, isto é, operar apelos ajuizados do discurso parcimonioso em contraste com um mundo sensitivo e agressivo. Burch (1973) nos mostra os elementos da surpresa rítmica estética no mal-estar, como componente intrínseco do discurso realista cinematográfico:

Ora, julgamos que surpresa e mal-estar, considerados assim, são dois dos modos mais moderados por que a imagem pode agredir a sensibilidade do espectador e que abrem caminho, por assim dizer, a toda uma gama de agressões de crescente intensidade (BURCH, 1973. p.147/148).

Percebe-se que Burch está colocando em perspectiva a lógica de um discurso moldado tecnicamente, no mais, pela evidenciação de imagens agressivas e despontuais. De novo, recorremos às narrativas pela chave descritiva de teor realístico. O efeito de real analisado por Barthes também antevia, ou preconizava níveis de agressividade na chave do desnudamento, que estamos pontuando, neste trabalho, no olhar em 21 gramas, como desintegração, a fim de entendermos a estetização fundada no desconforto de matriz social. 
Com isso, percebe-se que há no ideário de conflito em 21 gramas um instrumento robustecido por um discurso culturalista, pois sintetiza diferenças evidenciadas em uma lógica estrutural solta na perspectiva multidialógica ou multiprotagonista (cf. DELEYTO e AZCONA, 2010). Bordwell (2004, p. 35) pontua os impasses em torno do pós-modernismo ou do culturalismo contemporâneo como vínculo associativo da desintegração.

Mas, repitamos: a desintegração só terá sentido se associada a um apelo sensitivo de ideia realista. A vida real deve ser entendida, pois, como conseqüência política/cultural determinada pelo emblema naturalista, a desempenhar papéis de incomodadas visões e perspectivas. Nesse contexto contemporâneo (em expressões e termos controversos como a pós-modernidade ou o multiculturalismo), Feldman (2008) nos alerta para a profusão de fenômenos alicerçados no real: flagras de toda ordem, reality shows, lógicas midiáticas calcadas em "impressões de autenticidade das imagens amadoras".

Essas impressões novas inserem na produção audiovisual contemporânea - e nos filmes de Iñárritu, por exemplo - a edificação de novas transparências, a reforçar o real em sua carcomida inconveniência, mas envolto também nos processos de cisão de demandas idílicas e morais, como no caso de Jack, Paul e Cristina em 21 gramas.

\section{O DETERMINISMO DE PACTO}

O determinismo, segundo Deleyto e Azcona (2010) está totalmente vinculado a um destino moldado pela resistência ou à presença da morte. Nesse sentido, a dor alojada de Jack se coaduna também à ideia potencializadora da morte em Cristina e Paul. Há, com isso, evidentemente, uma preconização de pacto de realidade na ideia determinada e legitimada de uma narrativa naturalista. Naturalismo no sentido de explicitar o apelo realista (FELDMAN), por criar, como vimos, pontos testados em uma verossimilhança aguda.

Tal pacto de realidade irá se sobrepor, principalmente, no tempo que pune. O tempo vital cristalizado moldará os personagens, a saber:

Jack: cadeia $=>$ purificação $=>$ acidente $=>$ cadeia $=>$ purificação (pela punição)

Paul: doença $=>$ acidente $=>$ purificação $\Rightarrow$ doença $\Rightarrow$ purificação (pela morte)

Cristina: felicidade $=>$ acidente $=>$ luto $=>$ purificação (pelo amor)

Nessas três etapas de vida, o caos do acaso surge como um emblema representativo de realidade bruta, por se emparedar à lógica do fragmento fruído e cíclico. Tal estratégia audiovisual do cinema mundial contemporâneo será observada por Bordwell (2004) como sintoma culturalista de mundo, estendido a uma visão de nuances pós-modernas. Desse modo, as purificações esquematizadas acima são instrumentos essenciais para entendermos os rumos 
do cinema contemporâneo (tanto o industrial como o de retrato mais independente); é, não sem coincidência, que o cinema de Iñárritu se sobressai como uma noção advertida de real, mas também isentada pela lógica "amadorística das imagens".

Esse zelo por um mundo fragmentado em mosaico é peça de legitimação da imagem mais austera, mais verdadeira, com mais "transparência". Essa sensação de legitimação, como abismo, desintegra o tempo dos personagens e reforça espaços cênicos de natureza distinta e de aparatos intensamente descritivos (hospital, lar, danceteria, bar, igreja etc.). As instituições desempenham cisões ou dualidades estampadas no percurso, outro item fundamental para percebermos a transparência de matriz realista/naturalista, em 21 gramas.

Nota-se, na dualidade entre claro e escuro, e em presença de espaços cênicos cinzas (como a piscina da sequência final, ao lado do descampado próximo do motel em que Cristina e Paul se hospedam à espreita de Jack). Há ali, por exemplo, a evidenciação de uma aposta desintegrada e absurda de redenção, já que permite, pelo tom desfocado e nebuloso da fotografia de Rodrigo Prieto, ilustrar a punição redentora de Paul e Cristina, mas, ao mesmo tempo, resumir o quão maléfica é a tinta do inferno social.

Com essa demarcação e reforço da desintegração ética dos personagens (em seu destempero desintegrativo), a fragmentação também é um elemento de determinação do estado das coisas, pois há a compartimentação de eventos distintos, rememorando o percurso de contato íntimo com a sociedade, enquanto matriz naturalista (peguemos como exemplo as obras mais emblemáticas de Emile Zola). Ou seja, a punição do (e no) espaço se emana na pulsação descritiva com o chamamento da purgação e do périplo sofrido.

O tal pessimismo em Iñárritu pode (e deve) ser entendido, justamente, na colocação de um epicentro (no caso, um acidente de trânsito fatal) que gera sensações tão desgastantes, a partir de espaços naturalistas localizados e planejados na degradação. Essa exatidão é fruto da investigação dos detalhes próprios do naturalismo, no mais. Grosso modo, esta característica naturalista irá permear o "fora do lar" como o ambiente dos infernos, ao contrário da fraternidade ensejada do sofá da conciliação ou da cama acolhedora.

No entanto, em 21 gramas, esta tarefa atribuída ao lar é ambígua, na medida em que nele os sofrimentos são vividos na proposição da "amputação" social ou no salvacionismo. Nesse sentido, Jack é violento com os filhos; Cristina faz de armários, estantes e gavetas paradeiros de despensa de drogas; Paul perambula nos cômodos ordeiros, negando a paternidade (almejada pela esposa Mary) e a sobrevivência.

Nota-se, portanto, que o acidente vitima a todos, e Jack parece ser o calcanhar de Aquiles da desintegração que rivaliza, paradoxalmente, com o convívio burguês de Paul e Cristina. Esses convívios tão conflituosos entre Jack, Paul e Cristina são fases dicotômicas, ainda assim, para se instruir um "peso de realidade" (XAVIER, 2008, 42), enquanto dispositivo naturalista de tendência 
clássica e de gênero. Entretanto, a aventura suspensiva de 21 gramas é desconfortante, em sua marca naturalista, justamente por se erigir de elementos descritivos de alta carga valorativa e se desenhar em uma estética de apelo (ou de choque) amador (ou documental). Assim, o espaço cênico representado se transforma em síntese da imagem dita naturalista ao propor sensações totalmente realistas, ou ainda no discurso que se estabelece como vínculo do que é mostrado pela força imagética. Ou nas palavras de Aumont (2002):

O realismo é uma tendência, uma atitude, uma concepção, em suma, uma definição particular da representação que se encarna em um estilo, em uma escola [...] esses diferentes estilos realistas são evidentemente determinados pela demanda social, e particular, ideológica (AUMONT, 2002, p.209/210).

A terminologia ideológica desempenha aqui um atributo de entendimento da realidade com a contenção edificada no estado transparente das coisas, ratificando, no mais, a evidenciação de construção rítmica do mundo. A narrativa fragmentada de 21 gramas exacerba a noção realista por que pontua os ritmos desconexos de um tempo (ou de tempos, para sermos mais diretos) em costumeira desintegração ou desconstrução. Eis a aparente fragilidade da realidade estampada em sua autenticidade. Segundo Feldman, o apelo realista, e seu enuviamento de transparência, é sintoma de um mundo cada vez mais prenhe de aceleração vital desconfortante e desconfortável.

\section{ENTRE A REDENÇÃO E O INFERNO: O DESCONFORTO DO PÉRIPLO}

Há três chaves para entendermos como os personagens principais de 21 gramas se evidenciam como "frutos" da fugacidade desmedida: Vingança, Autoflagelo e Suicídio.

Estas três marcas substantivadas irão se atrelar profundamente a códigos evidenciados pelas instituições e legitimados por dispositivos de base descritivas, naturalistas e realistas de toda sorte. Assim, identificamos alguns elementos e emblemas e suas funções descritivas na narrativa:

Arma de fogo: o contato de Paul com o universo próximo de Jack;

Discurso religioso: o contato de Jack com a aceitação do sossego social;

Baladas: o contato de Cristina com as drogas, ingredientes de torpor após a morte da família;

O discurso científico: o contato de Paul com o "juridiquês" médico;

O desajuste familiar: o contato de Jack com o medo dos filhos; 
A medicina e o hospital: o contato dos personagens em momentos de perda e de retomada;

Os descampados de subúrbio: o contato de Jack com seus subempregos citadinos;

Percebe-se nessas avaliações e nesses papéis atribuídos, uma clara evidenciação taxativa de função social. Essas funções são quebradas pela desordem dos seus respectivos papéis e pelo mosaico em perspectiva.

Por isso, a quebra permitirá a todos eles se enveredarem pelas marcas aqui elencadas:

\begin{tabular}{|l|l|l|}
\hline \multicolumn{1}{|c|}{ Vingança } & \multicolumn{1}{c|}{ Autoflagelo } & \multicolumn{1}{c|}{ Suicídio } \\
\hline Jack: negação da crença & Punição restritiva & $\begin{array}{l}\text { A cela da prisão deteriora- } \\
\text { da }\end{array}$ \\
\hline $\begin{array}{l}\text { Paul: o reconhecimento do } \\
\text { amor de Cristina }\end{array}$ & $\begin{array}{l}\text { As reações adversas do } \\
\text { transplante }\end{array}$ & $\begin{array}{l}\text { O elo "eterno" com Cristi- } \\
\text { na }\end{array}$ \\
\hline $\begin{array}{l}\text { Cristina: a punição desmedida } \\
\text { para Jack }\end{array}$ & $\begin{array}{l}\text { A drogadição e negação so- } \\
\text { cial }\end{array}$ & $\begin{array}{l}\text { A anteposição nascimento } \\
\text { X morte }\end{array}$ \\
\hline
\end{tabular}

A partir desse desenho lógico de percurso, confundido com uma espécie de marca naturalista (no sentido da degradação/purificação) e com uma ética de embaralhamento de vozes distintas, tem-se um modelo antitético de idealismo/projeção e de "dura" condição real:

\begin{tabular}{|l|l|l|}
\hline & \multicolumn{1}{|c|}{ Redenção } & \multicolumn{1}{c|}{ Inferno social } \\
\hline$\underline{\text { Paul }}$ & Amar Cristina & Matar Jack \\
\hline$\underline{\text { Jack }}$ & Cuidar da família & Aceitar a condição marginal \\
\hline Cristina & Matar Jack & Aceitar o intangível e o vazio \\
\hline
\end{tabular}

Talvez este sistema dê conta - de forma condensada - da visualização do apelo estético do desconfortável, ou seja, como a estética do desconforto evidencia um entendimento de mundo que não apenas os do choque. $A$ irrascibilidade da relação de Cristina com Paul demarca um profundo mal-estar - principalmente para ela - na sedimentação amorosa, ao mesmo tempo em que demonstra, por exemplo, os motivos da vingança a Jack (o "assassino' de sua família, e o "monstro" social por natureza). A cultura da violência impõe - pela narrativa costurada no acaso - uma humanidade desuniforme, que se demonstrará de modo mais impactante na busca incessante de suplício (fundamentalmente do "pária" Jack), do autoflagelo e da negação de vida. Esta negação de vida, no mais, pode ser vista aqui como mais um elemento de luta da fragilidade ante um inferno desajustado de matizes essencialmente humanos, contudo vis. 


\section{O DESCONFORTO É ESTÉTICO - E SOCIAL}

A noção de fragmentação sugere um mundo compartimentado, por isso diverso. A diversidade, no entanto, é mãe do desconforto, pois reforça aspectos imbuídos de conflitos e excitação (de reconhecimento cultural ou não). A diversidade de temas é fio estético e também social. Como vimos no início deste trabalho, a sensação de fragmentação pressupõe um mundo dividido e fraturado ante a globalização que estreita os territórios.

Esse debate, no mais, localiza as transições da própria mídia contemporânea em seus códigos de intensa absorção da realidade, e como embaralhamento das instâncias de representação do real.

Ou seja, como nota Burch (1973), a agressividade pontua outro aspecto de representação da realidade - no cinema - na qual a imagem deve ser condicionada à pulsão da realidade dura e carcomida dos emblemas contemporâneos. Nesse filão, ademais, é que se configura uma prática endereçada de fratura, de fragmentação, em que o mosaico só sintetizará, com grande força, o que estamos chamando de diversidade.

Além disso, a diversidade está atrelada a fenômenos comportamentais, nos dias que correm, a saber: confronto, pane das identidades e a (o retrato) leitura (cobertura) da morte.

Ora, nesse esquema há uma intima ligação com o aparato estético do desconforto de matriz cultural e social. Em 21 gramas, a desintegração, inserida na dualidade entre o fio redentor e a descida naturalista aos infernos de demanda social, reforça as conseqüências do processo de sangria e descompasso ou o desassossego estampado pelo desalento - às vezes até caricatural e expressionista - explicitando, pelo mosaico acelerado da música pop e do ambiente urbano, os macetes do turbilhão da própria celebração contemplativa.

Assim, os momentos de purificação ou de contemplação em 21 gramas são costurados/feitos/estampados na luta diária, em outro deslocamento de caráter antitético, ou seja, na distinção entre a brutalidade da vida e o lance de contemplação materializado na poetização do cotidiano, reforçando, deste modo, aspectos intrínsecos aos estratos do audiovisual contemporâneo: as novelas, as séries da TV, as narrativas documentais e jornalísticas etc. Esse sintoma é estético, pois pontua o desnível ético de nossa proposição ante o real, o famigerado real.

Por isso, o desconforto em 21 gramas é estético e também social, pois carrega - com grande força, é bom que se diga - todas as características do desalojamento perante o grande capital globalizado. Esse estado de afinação e retrato se localiza na cidade (de tom carcomido e naturalista), já que a urbe é o sintoma perfeito da encenação do mosaico representativo da fragmentação, ou seja, é na cidade que vai se desenhar o doce narrar do espaço deteriorado e muito-representativo, ou, para ficarmos nas palavras de Deleyto e Azcona, multiprotagonista. 
Os personagens principais de 21 gramas percorrem suas lutas em compartimentos temporais e espaços cindidos. Com isso, 21 gramas se mostra como um "retrato" das inconveniências do confronto, pois se aproxima - em sua pretensa documentalidade, ou em seus níveis de distinções técnicas e estéticas - ao comportamento vaticinado do modo social, a estampar as mazelas e desajustes da sociedade urbana.

Por isso, a realidade é mostrada e consubstanciada perante um mundo em desconforto. Assim, o desconforto é social e estético, pois, retomando, em 21 gramas solidifica-se o confronto (Paul em confronto com Jack, no antagonismo da relação com Cristina em sua desintegrativa função social, no mais) com o desmantelamento das identidades (O sereno Paul se transforma no idiota fugidio e autocorrosivo na relação com a morte sem lastro e sem freio; e Jack na sua tortuosa negação/afirmação de Deus, a um mundo/cidade deslocado de intenções salvadoras e redentoras) e com a preconização da morte.

A preconização da morte é essencial para se entender a divisão entre a redenção e o inferno social. A finitude, personificada na morte, elucida os aspectos vitais do drama como suporte e do sentido da fragmentação narrativa, em perspectiva realista e descritiva, com grande relevância.

Assim sendo, a estética do desconforto em 21 gramas revela, pois, vários sintomas, entre eles:

$\Rightarrow$ O sintoma de uma multiculturalidade: quando trata de um cinema intercultural calcado na estética do hibridismo de forma e conteúdo, e porque ratifica uma expressão de Stam (2010): o hibridismo funcionando como a "redenção estratégica do inferior e do desprezado";

$\Rightarrow$ O sentido de novas identidades: na medida em que a voz dada a personagens é inserida na lógica melodramática e clássica, e até do inconveniente paradoxo da moralidade cristã, pelo desconforto de relação social;

$\Rightarrow \mathbf{O}$ sintoma da solidão urbana: as seqüências finais, envoltas na piscina cinza e vazia, no descampado ao redor de um motel "carcomido", polarizam com os lares atormentados e ensejados na pressão/solidariedade. $O$ espaço do clímax, em 21 gramas, é o ambiente classificado - e exagerado - da solidão

Com esses sintomas escancarados em 21 gramas, percebemos que as fraturas do mundo, sintetizadas pelo périplo de Jack, Cristina e Paul se coadunam à natureza calcada no destempero da palavra diversidade, que como nota Stam:

A natureza multipista da mídia audiovisual a capacita a orquestrar histórias múltiplas, até contraditórias, temporalidades e perspectivas. Ela não oferece um “canal de história”, mas múltiplos canais para representações históricas multifocais e de múltiplas perspectivas (STAM, 2010, p.125). 
Essa notação de Stam se mostra, de certa maneira, alinhada à dimensão que Tucherman (2006) estabelece quando polariza a identidade presente no rosto dos personagens de 21 gramas à custa das mais fabulosas comparações, como por exemplo A outra face (1997), de John Woo. Guardando, com certa prudência as convergências e divergências de apropriação do cinema de John Woo com o de Iñárritu, Tucherman fundamenta uma visão identitária contemporânea correspondente, grosso modo, à dificuldade contemplativa do apareIho midiático multifocal e heterogêneo. Eis o dilema do mundo fraturado por instâncias tão aceleradas e fragmentadas. Paradoxalmente, no entanto, o rosto adquire um papel essencial nas narrativas presentificadas de real, pois são eles, no mais, que elucidarão a identificação dos códigos e cisões culturais.

O processo de hibridização cultural, em suas fatias de multiculturalidade, dá-se pela ideia, também controvertida e "atrevida", de um debate intercultural de grande monta. 21 gramas escancara esse termo porque as sensações ali desmontadas são percepções de um mundo amplamente desconfortante, e aparentemente sem saída; mas elucida a beleza humana, justamente na exatidão de um melodrama intrínseco e presente.

\section{CONSIDERAÇÕES}

A chave do percurso em 21 gramas se dá por um ideário de saga, em que a estética do desconforto se coaduna com vários aspectos: (1) a descrição exerce papel fundamental de relatar o mundo real inconseqüente por que evidencia, justamente, os blocos narrativos e fragmentos, no mosaico da cidade grande que vitima os personagens; (2) a partir daí, a fragmentação multiperspectívica se estabelece como um jogo demarcativo ao qual os três principais personagens traçarão uma luta total entre família alojada e mundo pulsante no "lá fora': na rua e na vida como cenário de suas mutações; (3) esse caminho de nuances estampadas no realismo deve ser entendido por um percurso de sofrimento, de périplo, nas interpretações carregadas de ressentimento, no desentendimento rítmico das fugas etc.

A realidade em 21 gramas é autenticada por um efeito presente na lógica fragmentada contemporânea, reforçando em tal apelo uma propulsão de mundo desajustado. Esse desajuste legitimado pelo real corrobora para a percepção da fragmentação, do mosaico e, até, do hibridismo de fórmulas.

O hibridismo pode ser encarado como mistura, mestiçagem, variedade, mas também pode ser visualizado como obscurecimento, ou melhor, embaraIhamento das vozes distintas. Esse embaralhamento, nos mais, servirá como demarcador de antíteses importantes: a principal, aqui mencionada, é entre a redenção almejada e o inferno ratificado. Os gestos em 21 gramas são envolventes na medida em que escancaram as divisões pela marca do desconforto. 
Nesse sentido, a polarização entre redenção e inferno só pode ser entendida por um desconforto crescente, materializado, técnica e esteticamente, pela aceleração narrativa e discursiva da fragmentação. Iñárritu evidencia, principalmente, as marcas substantivas desse processo: a vingança e o sufocamento da morte recusada ou também buscada.

Com essas marcas de desalento e tristeza, a tênue poeticidade surge no enuviamento da humanidade alçada na poetização do "peso da morte" e no contato de 21 gramas com outras obras de Iñárritu/Arriaga: em Amores Brutos, na urgência de legitimar o real bruto; e em Babel, na urgência de revelar o pessimismo social, e desnudar o otimismo do mundo sem fronteiras.

Esses desnudamentos e essas revelações se dão, sempre, com a presença/ausência da família, numa (des)ordem que parece estar atrelada, com intensa participação/fundamentação, pelo (e no) melodrama, ratificando, assim, uma identidade cinematográfica preocupada com a tragédia social e com o delírio realista, e promulgada com a abordagem incessante do real.

\section{REFERÊNCIAS}

21 GRAMAS (21 grams), de Alejandro González Iñárritu, 2003, 124 min.

AUMONT, J. A imagem. 7.ed. Campinas: Papirus, 2002.

BARTHES, R. O efeito do real. In: ___ _ O rumor da língua. 2.ed. São Paulo: Martins Fontes, 2004.

BORDWELL, D. Estudos de cinema hoje e as vicissitudes da grande teoria. In: RAMOS, F.P.

(org.). Teoria contemporânea do cinema. Volume I. São Paulo: Senac, 2004.

BURCH, N. Praxis do Cinema. Lisboa: Estampa editorial, 1973.

DELEYTO, C; AZCONA, M. Alejandro González Iñárritu. Chicago: Illinois Press, 2010.

FELDMAN, I. O apelo realista: uma expressão estética da biopolítica. In: HAMBURGUER, E. et al. Estudos de cinema Socine. São Paulo: Fapesp; Socine; Annablume, 2008.

STAM, R. Para além do Terceiro Cinema: estéticas do hibridismo. In: FRANÇA, A.; LOPES, D. (orgs.). Cinema, globalização e interculturalidade. Chapecó: Argos, 2010.

TUCHERMAN, I. Imagem, rosto e identidade: relações instáveis no mundo tecnológico contemporâneo. Rio de Janeiro: Revista Logos $n^{\circ} 24$, ano 13, $1^{\circ}$ semestre 2006.

XAVIER, I. O discurso cinematográfico: a opacidade e a transparência. 4.ed. São Paulo: Paz e terra, 2008. 


\section{Cláudio Rodrigues Coração}

Doutorando em Comunicação: Meios e processos audiovisuais pela Escola de Comunicação e Artes da Universidade de São Paulo - ECA/USP. Mestre em Comunicação pela Universidade Estadual Paulista - UNESP. Jornalista. Professor do curso de Comunicação Social da Universidade Paulista - UNIP (Campus Bauru) e Faculdades Integradas de Bauru - FIB. Coordenador auxiliar do curso de Jornalismo da UNIP Bauru. 